\title{
An Evidence Based Study of the Different Factors that Influence the Formation of Hammer Transfer Stains in a Crime Scene
}

\author{
Samir Kumar Bandopadhyay* and Nabanita Basu
}

Department of Computer Science and Engineering, University of Calcutta, India

\begin{abstract}
Weapon transfer stains in a crime scene are often difficult to interpret. Given the large number of hammer hit events that take place each year, this work is largely aimed at analyzing the different factors that influence and distort regular hammer transfer stains. Different physical mechanisms under identical conditions influence the formation of distinct transfer stain patterns. This is the basic highlight of this study. By experimentation, the authors are of the view that the quantity of blood attached to the surface area of a hammer, the surface area of the hammer exposed to blood, the dimensions of the hammer, the angle of inclination at the time of fall, hardness of the target surface, friction coefficient of the hammer material, texture of the target surface influence the transfer stain formed. Again the velocity of hit, the undulations in the hammer, the depth of blood pool, hammer weight all have significant effect on the transfer stain pattern formed. The significance of the height of fall and the edge that touches the target surface first, cannot be particularly ruled out in analyzing hammer transfer stain patterns. The relevance of the article lies in the fact that analysts having clear idea of how these different factors could affect the formation of different weapon transfer stain patterns, shall be in a better position at understanding the probable mechanism that might have led to the formation of the stain. This knowledge is transferable to the study of other murder weapon transfer stain interpretation and shall aid proper sequencing of segments in a criminal event.
\end{abstract}

Keywords: Murder weapon, transfer stain, bloodstain pattern, hammer, head hit, free fall.

\section{INTRODUCTION}

Locard's exchange principle states that "every time an individual makes contact with another person, place or thing, it results in an exchange of physical materials" (Welding, S. 2012). Locard believed that no matter what a perpetrator does or where he goes,by coming in contact with things at or around a crime scene he can leave all sorts of evidence, including DNA, fingerprints, footprints, hair, skin cells, blood, body fluids, pieces of clothing fibers and more (Welding, S. 2012). While the criminal leaves something at the crime scene he is also expected to take something away from the scene with him (Welding, S. 2012). On a very loose connect it might be said that when killing an individual with a hammer hit the criminal might take away the murder weapon with him but at the same time he might end up leaving behind bloody stains of the blood bearing hammer at the crime scene. 'A bloodstain resulting from contact between a blood-bearing surface and another surface' has been termed as 'Transfer Stain' by the International Association of Bloodstain Pattern Analysts (IABPA) (SWGBPA, 2009). Thus this work is particularly directed at studying hammer transfer stain patterns at a crime scene.

On December 13, 2010, Dave Toplikar's report reinforced the importance of proper recording and

*Address correspondence to this author at the Department of Computer Science and Engineering, University of Calcutta, India;

E-mail: skb1@vsnl.com hence interpretation of weapon transfer stains at a crime scene (Toplikar, D. 2010). Dave's report in the Las Vegas Sun highlighted how the presence of a hammer imprint in blood pool was capable of influencing the decision of the jury and the fate of Mr. Edward Preciado Nuno, an ex-FBI special agent (Toplikar, D. 2010). While Daniel Holstein, senior crime scene analyst in Metro police and a certified expert in bloodstain pattern analysis, gave the case a new dimension by focusing on the hammer imprint that matched the size of the hammer that lay close to the apparent victim's hand, Thomas Pitaro the defense attorney clearly marked out that the hammer imprint theory was not mentioned in the police report and was only added much later (Toplikar, D. 2010). There are two lessons to be learnt from the juridical proceedings of this particular case. Firstly, transfer stains often go unattended and hence unrecorded by most law enforcement officials. Secondly, when analyzed in relation to suspect, eyewitness testimony or other relevant circumstantial evidence, weapon transfer stains could actually give criminal juridical proceedings a new dimension (Toplikar, D. 2010), a new perspective.

The paper aims at studying hammer transfer stains in particular because of the easy availability and usability of hammer round the world. This very reason probably makes hammer a murder tool of choice among criminals over the world like Adam Moss(Sioux City, lowa, USA) (Blanco, JI, \& Adam Moss 2014), Alexander Yuryevich Pichushkin (Moscow, Russia) 
(Blanco, Jl, et al. 2014), Brian Blackwell (Merseyside, England, UK) (Blanco, Jl, et al. 2014), Christine Schürrer (Arboga, Västmanland County, Sweden) (Blanco, Jl, et al. 2014), Kampatimar Shankariya (Jaipur, India) (Blanco, Jl, et al. 2014), Ma Jiajue (China) (Blanco Jl, et al. 2014), Maoupa Cedric Maake (Johannesburgo area, South Africa) (Blanco, Jl, et al. 2014). In 2011, The Federal Bureau of Investigation (FBI) chart reported that the number of individuals killed (496) by blunt objects (such as club, hammer, golf stick, candle-stand etc.) by far superseded the number of individuals killed by rifle or shot gun (Washington CBS Local, 2013). With regard to the study of hammer transfer stains, it might be interesting for the reader to know that as per the FBI chart figures the number of individuals killed by hammer or club hit by far outnumbered the number of individuals killed by rifle or shot gun (Washington CBS Local, 2013).

Given the large domain of possible hammer transfer stains in a messy, cluttered crime scene, in this paper the authors have attempted at providing evidential proof for certain hypotheses relevant to the study of hammer transfer stains. The hypotheses were generated on the basis of author experience and case study.

\section{LITERATURE REVIEW}

In the domain of Bloodstain Pattern Analysis, the contributions of Professor MacDonell to the research and interpretation of bloodstain patterns at a crime scene, since 1971, stand integral (James, SH, et al. 2005) (James, SH, 1998). T. Bevel and M. Gardener in their book on 'Blood Stain Pattern Analysis $3^{\text {rd }}$ editionAn Introduction to Crime Scene Reconstruction' have attempted at drawing up an explicit taxonomy based classification of bloodstain patterns (Bevel, T, \& Gardner, RM, 2002). Along with the study of the variation of bloodstain patterns formed on different textured surfaces (i.e. plain/smooth, rough, porous etc.) they have also provided valuable insights on how bloodstain patterns vary with difference in impact angle, fall height, target surface properties, quantity of blood etc. (Bevel, T, \& Gardner, RM, 2002). Apart from briefing on the importance of the target surface texture and murder weapon dimensions in the formation of a stain, they have also provided important aids for sequencing available stain patterns at a crime scene in accordance with other relevant circumstantial evidence (Bevel, T, \& Gardner, RM, 2002). However, certain aspects or rather certain theories/ideologies represented in the book stand debatable. For example, the International Association of Bloodstain Pattern Analysts already has a list of bloodstain pattern terminology in place that is widely accepted and used within the community of Bloodstain Pattern Analysts, so as per Dr. R. R. Ristenbatt III, a new terminology as also bloodstain pattern classification system was totally unnecessary (Ristenbatt III, RR, 2009). In this regard, the bloodstain classification system put forward by James et al 2005 stands much more acceptable among bloodstain pattern analysts (James, SH, 2005). Dr. Brodbeck's article on 'Introduction to bloodstain pattern analysis' provides important practical guidelines for documentation and interpretation of bloodstain patterns at a crime scene (Brodbeck, S, 2012). Forensic Science particularly deals with presentation of evidence within a juridical setting. On similar lines, Stuart $\mathrm{H}$. James's book on 'Scientific and Legal Applications of Bloodstain Pattern Interpretation' puts down rules for presentation of uncontaminated, relevant bloodstain pattern evidence within a juridical setting (James, SH, 1998). Such evidence might be relevant in proving or disproving the statement of the suspect, bystander or the eyewitness (if any). Again such evidence could also be effectively used to support or contradict the probable reconstruction put forward by an expert witness. The literature on bloodstain pattern clearly elucidates scientific methods for predicting the area of origin, point of convergence, number of blows struck, relative positions of perpetrator, victim and bystander (if any) based on various bloodstain patterns found at a crime scene. To mathematically calculate the area of origin of an impact spatter stain, it is integral to select geometrically well formed elliptical stains. Illes and Boue developed a statistical model to establish bloodstain spatter selection criteria in an impact spatter stain using the data collected from different impact spatter stains created within laboratory environment (Illes, M, \& Boue, M, 2011). As the manual stringing method used for estimating the area of origin of the impact spatter formed often leads to contamination of surrounding relevant evidence, Shen, Bostrow and Cipolla developed an automatic algorithm for localizing the origin of an impact spatter in 2D (Shen, AR).

This study is particularly based on the work undertaken by Barksdale, Sims and Vo (Barksdale, et al. 2004). They developed a reference array of knife impressions and compared them with the knife transfer stains obtained from two real life crime scenes (Barksdale, et al. 2004). Knife impressions are often quite pronounced for an analyst to match them up with a suspected knife.The weight of a knife is highly 
unlikely to produce a void pattern in a blood soaked surface by reverse capillary action (Barksdale, et al. 2004). The document put together by the University of Western Australia on Blood Spatter (CLT, 2014) and Dr. J.J. Nordby's 'Basic Bloodstain Pattern analysis Text' (Nordby, JJ, 2006). give a precise yet lucid description of the different forces that control the formation of the different bloodstain patterns in a crime scene. A lucid scientific explanation on the free fall of elongated and elongated top heavy objects based on the principles of physics was provided by Rod Cross (Cross, R, 2006). Hammer physics in Mollett reports highlight the physics that underlie hammer hit incidents in a crime scene (Hammer Physics, 2013). Press publications as also court proceedings on criminal cases involving hammer hit have been methodically compiled and made freely available by J. Blanco on the website Murderpedia.org (Blanco, JI, 2014). Access to this website was indeed beneficial for the authors in understanding and analyzing certain relevant segments of the crime scene in question (Blanco, Jl, 2014).

\section{HYPOTHESES GENERATED}

The hypotheses were framed by the authors on the basis of experience, experimentation and study of criminal court proceedings. The hypotheses framed by the authors can be outlined as follows:

Hypothesis 1: The quantity of blood that adheres to a hammer as also the surface area of the hammer to which blood adheres to largely control the pattern of the hammer transfer stain. But, a totally blood drenched hammer does not ensure a full body transfer impression of the hammer on a plain non absorbent surface.

Hypothesis 2: If the velocity and acceleration of a hit vary, depending on the area that was hit an individual can very well expect to see different transfer stain patterns

Hypothesis 3: When a hammer undergoes free fall under gravity, one can expect to see changes /differences in bloodstain pattern owing to difference in fall height and mass of the hammer.

\section{METHODOLOGY}

This section can further be subdivided into the following subsections - Blood Procurement, Experiments conducted, Pitfalls/ Noise encountered in course of conducting the experiments and how the authors dealt with it.

\subsection{BLOOD PROCUREMENT}

The authors used porcine blood for the experiments because porcine blood is quite similar to human blood (Christman, DV, 1996 and Amin TM, \& Sirs JA, 1985). Blood was legally procured from Kolkata Municipal Pig Slaughter House, Tangra Kolkata, India. Given that fresh blood coagulates over time, 1100 IU of Heparin Injection was added to fresh pig blood to preserve the colloidal consistency of blood. It might be interesting to mention that adding anticoagulant does not alter the viscosity and specificity of the Non-Newtonian fluid, blood.

\subsection{Experiments Conducted}

At the very onset, a hollow coconut with a hair wig (refer Figure 1) was used to simulate the head hit event in a crime scene. The authors particularly attempted to reconstruct the event of back head hit in a crime scene. The hair wig was soaked in $20 \mathrm{cc}$. of pig blood in order to create the bloody hammer transfer stains one might expect to see after head hit.

By way of study of the juridical proceedings for several criminal cases and by conducting a brief survey of the available hammers at the local market, the authors prepared a list of 6 different hammers to be used in the study.

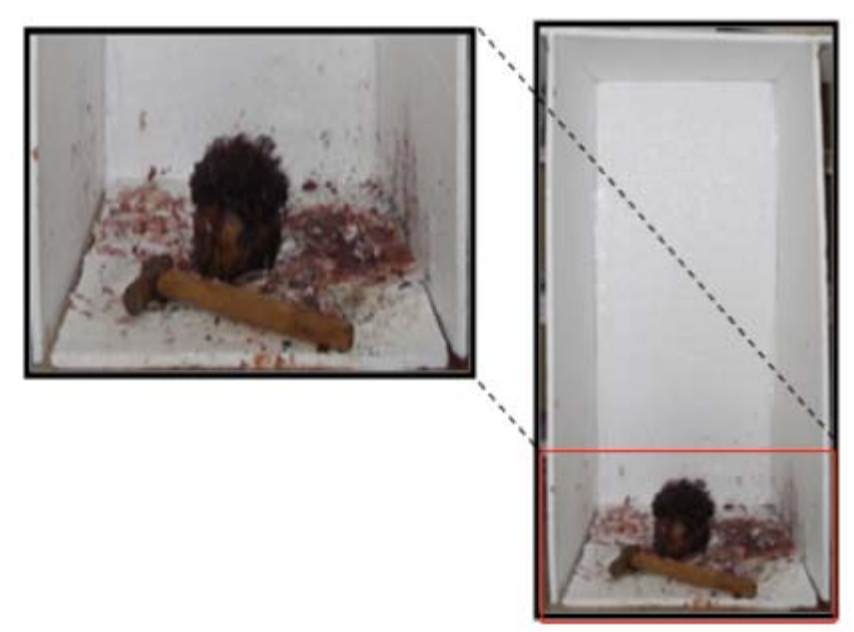

Figure 1: Experimental Setup replicating the event of a head hit. As the authors were not inclined towards recording the stains (particularly cast off and impact spatter patterns) formed on the walls and ceilings for a particular height of the victim, perpetrator, number of hits made by the perpetrator, hence this setup was constructed.

The experiment was performed in 2 phases. In the first phase the coconut shell was hit with each hammer consecutively for 10 times and then each hammer was dropped from a height of $40 \mathrm{cms}, 60 \mathrm{cms}$ and $80 \mathrm{cms}$ 
respectively. In order to minimize or control property damage the hammer was dropped on a paper sheet (A3 size) placed on a thermocol sheet (refer Figure 2).

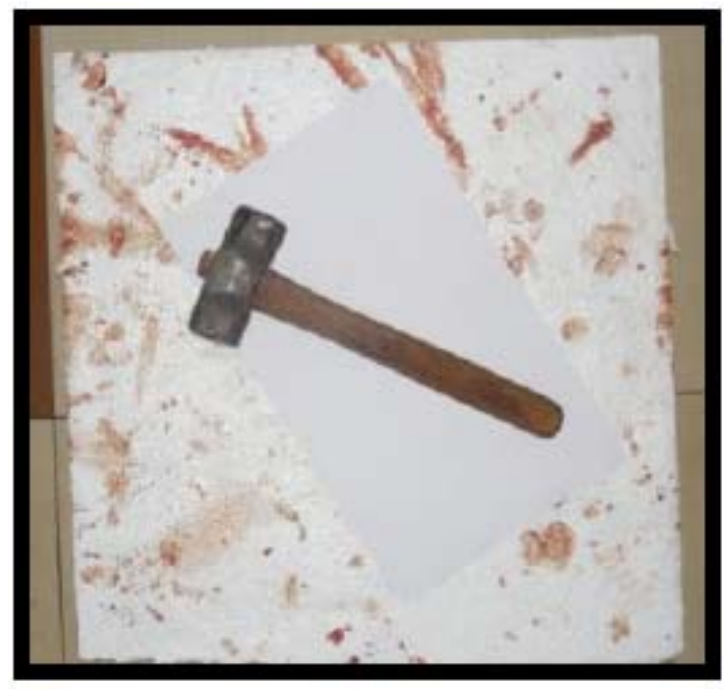

Figure 2: Thermocol sheet placed on the floor to avoid damage of the floor tiles. Paper sheet is placed on the thermocol sheet and hammer is dropped on the paper sheet by measuring the fall height from the top of the thermocol sheet.

The fall height was measured from the top of the thermocol sheet. In the next part of the experiment, each hammer was again used for 10 head hits, then dropped in a $30 \mathrm{cc}$. blood pool, picked up and again made to fall from a height of $40 \mathrm{cms}, 60 \mathrm{cms}$, and 80 cms respectively. The two incidents that the authors intended to recreate by way of the experiment can be outlined as follows,

Incident 1: The perpetrator hits the victim 10 times and the hammer slips and falls under gravity from a height of 40,60 and $80 \mathrm{cms}$ respectively.

Incident 2: The perpetrator hits the victim 10 times and the hammer slips and falls off from his hand under gravity and falls into a blood pool $(30 \mathrm{cc})$ (refer Figure 3). The perpetrator picks up the hammer and it yet again slips and falls off from the hand of the perpetrator from a height of 40,60 and $80 \mathrm{cms}$ respectively.

In the second phase, the bloody edge impression of each hammer was taken after 10 head hits. Two impressions of each edge were recorded in the course of the experiment. In the first instance, the hammer was simply placed on a plain/smooth non-absorbent surface (paper) with the bloody edge being the only contact point between the surface and the hammer for a brief period of 5 secs. In the second part of the experiment, after 10 head hits the paper surface was struck with the bloody edge of the hammer at a particular velocity. The paper surface wasn't hit with an extremely large force as because a full force hit was found to rupture the paper surface.

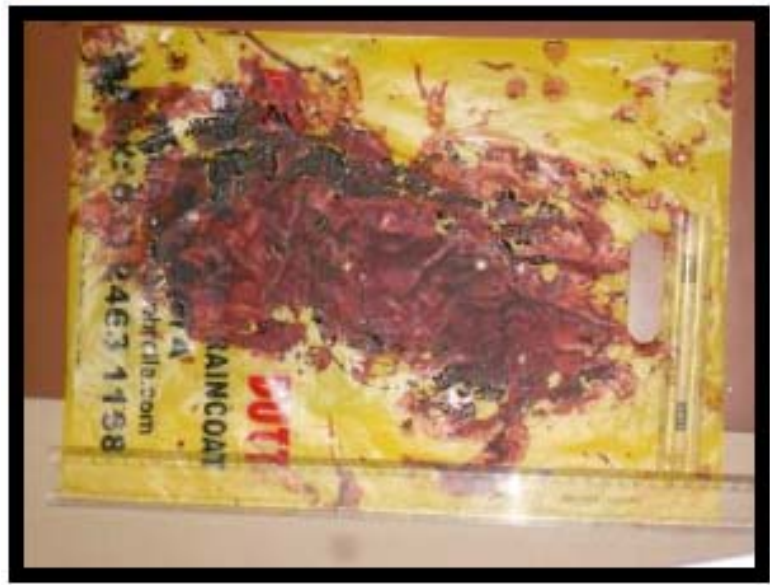

Figure 3: Dried up $30 \mathrm{cc}$ blood pool created on a plastic sheet. The blood pool was not created on paper as the paper surface would cringe on the drying of the $30 \mathrm{cc}(\mathrm{ml})$ blood pool.

The height of the victim/perpetrator was not taken into account in the study as the authors did not want to record the cast off, fingerprint transfer stain patterns that might be formed as a result of head hit.

\subsection{Pitfalls/Noise}

1. Given that there are hardly any research papers on the study of hammer transfer stains and head hit experiments, the authors designed the best possible ethical simulation of hammer head hit that they could achieve. However, the authors still stand unsure of how accurately the simulation mimics the event of a back head hit for a human being.

2. Although there are a wide array of hammers, but not all types are available in the market. So, the authors squared on a set of 6 different hammers based on the study of juridical proceedings of criminal cases in coherence with the availability of the hammers at the city marketplace.

3. In course of the experiment the hair as also the blood pool was found to dry up in part, so they were replenished as and when required.

\section{RESULTS}

Table 1 represents the front, side and isometric view of the hammers that have been used for the study. These views of the hammer have been recorded 
Table 1: Front, Side and Isometric view of the different hammers (Ball Peen, Sledge, Special, Brick, Claw, Cross and Straight Peen hammer) used in the study. [Head Weight: Sledge - 1kg; Ball Peen- 500 gms; Claw - 500gms; Brick-400gms; Cross and Straight Peen -250 gms; Special-250 gms][Front View of Hammer labeled as HF\#no.; Side View of Hammer are labeled as HS\#no., Isometric View of Hammer labeled as HI\#no] [Images were taken with Nikon Coolpix L610]

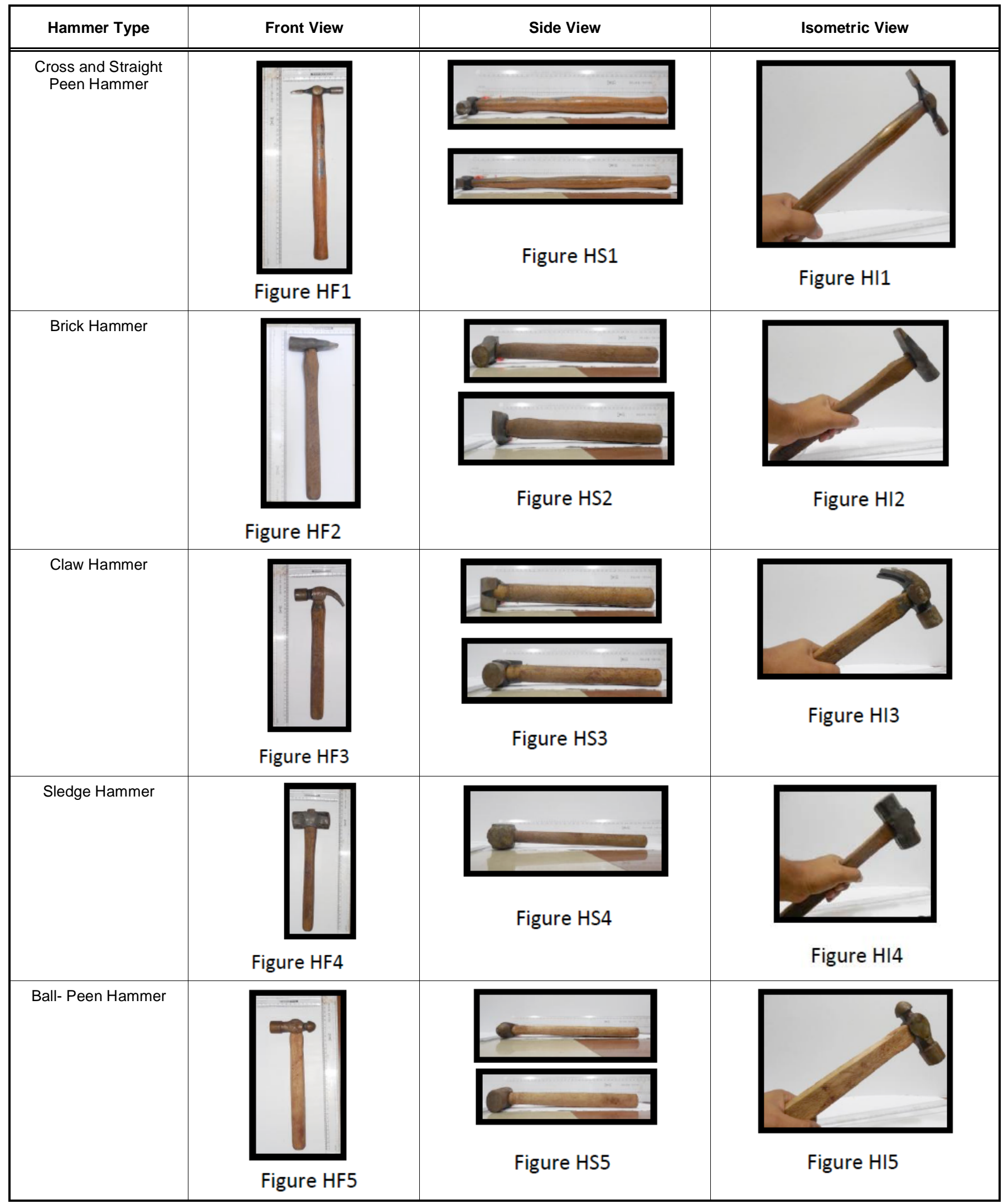


(Table 1). Continued.

\begin{tabular}{|c|c|c|c|}
\hline Hammer Type & Front View & Side View & Isometric View \\
\hline \hline Special Hammer & & & \\
& & & \\
& Figure HF6 & Figure HS6 & Figure HI6 \\
\hline
\end{tabular}

and hence presented to the reader/s so that he/they can have an idea about the dimension, edge of the hammers that have been used for the study.

The temperature and humidity values on the day of the experiment were also recorded. Table 2 represents the values recorded.

Table 2: Atmospheric conditions of the area where the experiments were performed

\begin{tabular}{|c|c|}
\hline Atmospheric Parameters & Values \\
\hline \hline Dry Temperature & $23^{\circ} \mathrm{C}$ (approx.) \\
\hline Wet Temperature & $26^{\circ} \mathrm{C}$ (approx.) \\
\hline Relative Humidity & $77-78 \%$ \\
\hline Wind Conditions & Not Windy \\
\hline
\end{tabular}

Table 3 represents the transfer stains formed when each of the hammers after 10 head hits were allowed to fall under the effect of gravity from a height of 40 $\mathrm{cms}, 60 \mathrm{cms}$ and $80 \mathrm{cms}$ respectively. Only results for 3 hammers have been displayed in this section, so as to avoid information overload.

Table 4 represents the transfer stains formed when each of the hammers after 10 head hits were dropped into a blood pool and then picked up and again dropped from a height of 40,60 and $80 \mathrm{cms}$ respectively.

Table 5 represents the edge impressions taken from each of the three hammers when the hammers after 10 head hits were placed bloody edge down on a piece of plain/smooth, non-absorbent paper surface for a brief period of 5 secs. The edge impression formed when the plain/smooth, non-absorbent surface was struck with a particular velocity by the bloody edge of the hammer was also recorded.

\section{DISCUSSION}

In the light of Hypothesis 1, if Figure HD1 and HW1 or for that matter HD3 and HW3 are compared it can well be observed that the bloody impressions cast in HW1 and other HW figures are more pronounced as compared to their counterpart HD figures. Due to forces of adhesion, blood molecules stick to the surface of the hammer edge when the hammer edge is used for 10 head hits (CLT, 2014). Owing to forces of cohesion, again blood molecules stick to each other (CLT, 2014). Now when the hammer is dropped face down into a $30 \mathrm{cc}$. blood pool, a greater surface area of the hammer comes in contact with blood molecules. So as compared to a hammer that has been used for approximately 10 head hits one can logically expect more blood molecules to be stuck to a piece of hammer that has been used for 10 simultaneous head hits followed by being dropped into a 30cc. blood pool and then picked up. Now again when these two bloody hammers having similar dimensions were allowed to drop from the same height, the blood spatter marks for the bloody hammer that had been initially used to hit the head 10 times were found to be much less pronounced as compared to the stains produced by bloody blood pool soaked hammer when it was dropped bloody face down. As the quantity of blood stuck to the blood pool soaked hammer as compared to the head hit bloody hammer was more, hence the blood in the first case forms a more significant spatter. Again, blood spatters only when other forces exceed the surface tension that holds the blood molecules together (CLT, 2014). The gravitational force with which the bloody hammer hits the surface exceeds the surface tension. Given the comparatively larger quantity of blood attached to the bloody face of the blood pool soaked hammer, blood was found to spatter more in its case. Thereby it can be concluded that the 
Table 3: The transfer stains formed on plain non-absorbent surface (i.e. paper) when each of different types of hammers were used for back head hit and then dropped from a height of 40,60 and $80 \mathrm{cms}$ respectively at different angles of inclination. [Figures of hammer dropped from different height are labeled as Figure HD\#number] [Images taken with a Nikon Coolpix L610 camera]

\begin{tabular}{|c|c|c|c|}
\hline Hammer Type & $\begin{array}{l}\text { After } 10 \text { head hits hammer was } \\
\text { dropped from a height of } 40 \\
\text { cms }\end{array}$ & $\begin{array}{l}\text { After } 10 \text { head hits hammer was } \\
\text { dropped from a height of } 60 \\
\text { cms }\end{array}$ & $\begin{array}{c}\text { After } 10 \text { head hits hammer was } \\
\text { dropped from a height of } 80 \\
\text { cms }\end{array}$ \\
\hline Ball Peen Hammer & \begin{tabular}{|l|} 
\\
$y-$ \\
Figure HD1
\end{tabular} & \begin{tabular}{|c|}
. \\
\\
Figure HD2
\end{tabular} & Figure HD3 \\
\hline Claw Hammer & \begin{tabular}{|l|}
$4^{4}$ \\
Figure HD4
\end{tabular} & Figure HD5 & Figure HD6 \\
\hline Sledge Hammer & \begin{tabular}{|c|} 
\\
\\
\end{tabular} & $\underbrace{\mid}_{\text {Figure HD8 }}$ & \begin{tabular}{|l|} 
\\
\\
\end{tabular} \\
\hline
\end{tabular}

Table 4: A tabular representation of the different transfer stains formed when each of the different hammers (Sledge, Claw, Ball-Peen) were used for 10 head hits and then subsequently dropped in a $30 \mathrm{cc}$. blood pool. The hammers were picked from the blood pool and subsequently dropped from a height of 40,60 and $80 \mathrm{cms}$ respectively on a plain, non-absorbent surface (paper in this case). [Figures of transfer stains formed after 10 head hits and subsequent dropped in blood pool are marked as Figure HW\#number] [Pictures taken with Nikon Coolpix L610]

\begin{tabular}{|c|c|c|c|}
\hline Hammer Type & $\begin{array}{l}\text { After } 10 \text { head hits, hammer was } \\
\text { dropped into a } 30 \mathrm{cc} \text {. blood } \\
\text { pool, then picked up and } \\
\text { dropped from a height of } \\
40 \mathrm{cms} \text {. }\end{array}$ & $\begin{array}{l}\text { After } 10 \text { head hits, hammer was } \\
\text { dropped into a } 30 \mathrm{cc} \text {. blood } \\
\text { pool, then picked up and } \\
\text { dropped from a height of } \\
60 \mathrm{cms} \text {. }\end{array}$ & $\begin{array}{l}\text { After } 10 \text { head hits, hammer } \\
\text { was dropped into a } 30 \mathrm{cc} \text {. } \\
\text { blood pool, then picked up } \\
\text { and dropped from a height of } \\
80 \mathrm{cms} \text {. }\end{array}$ \\
\hline Ball Peen Hammer & \begin{tabular}{|l|} 
Figure HW1 \\
\end{tabular} & Figure HW2 & Figure HW3 \\
\hline
\end{tabular}


(Table 4). Continued.

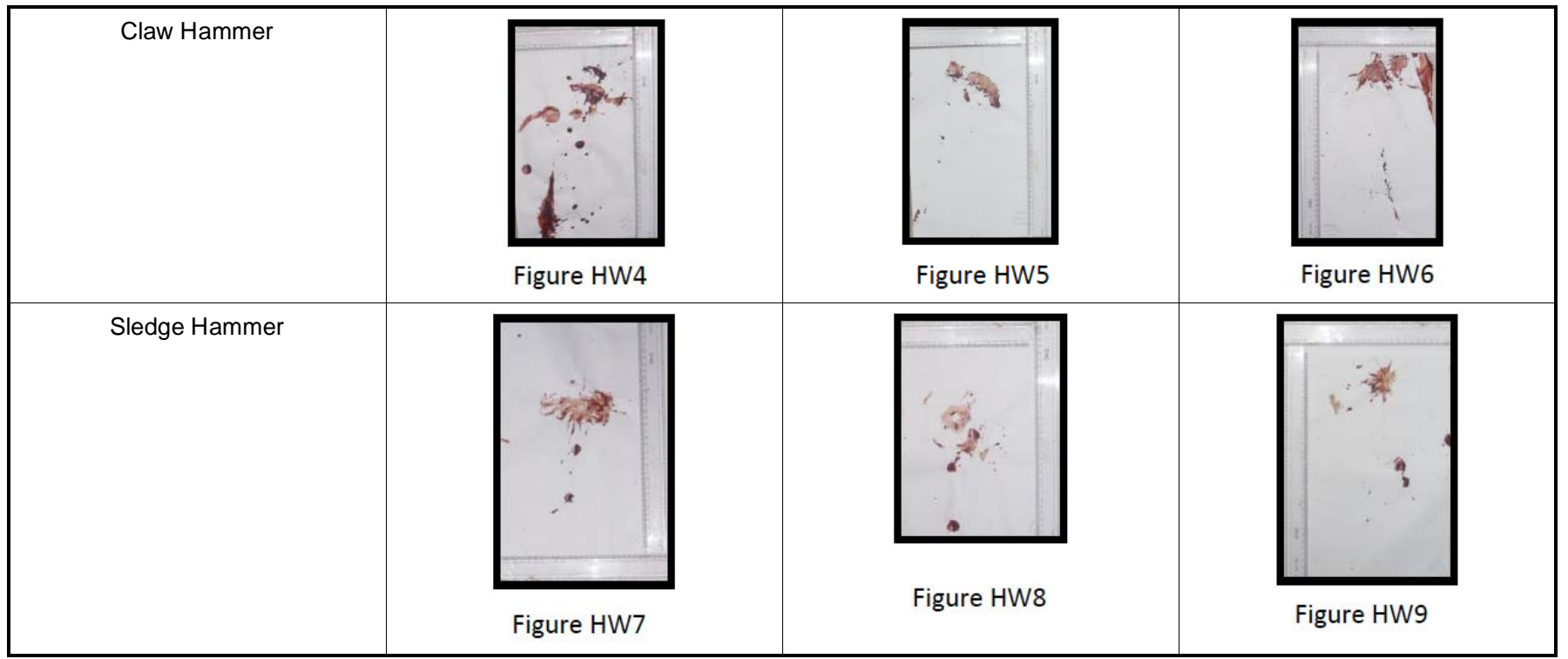

Table 5: The second column records bloody impressions of the bloody edge/s taken on plain, non-absorbent surface (paper) after that particular edge was used for 10 simultaneous head hits by placing the edge on plain, nonabsorbent paper. The $3^{\text {rd }}$ column records bloody edge transfer stains taken on paper after 10 simultaneous head hits by using the bloody edge to strike the plain non absorbent surface at a particular velocity. [Edge transfer stain images in the second column are labeled as Figure E\#number, Edge transfer stain images created by application of external force are labeled as Figure EF\#number in the $3^{\text {rd }}$ column] [Images taken with Nikon Coolpix L610]

\begin{tabular}{|c|c|c|c|}
\hline Hammer Type & $\begin{array}{c}\text { After 10 head hits, bloody edge of hammer was } \\
\text { placed on a plain, non-absorbent surface }\end{array}$ & $\begin{array}{c}\text { After 10 head hits, bloody edge of hammer } \\
\text { was made to strike a plain, non-absorbent } \\
\text { surface }\end{array}$ \\
\hline \hline Ball Peen Hammer & & & \\
\hline Claw Hammer & & & \\
\hline Sledge Hammer & Figure E1.1 & & \\
\hline
\end{tabular}

quantity of blood or blood molecules attached to the hammer, the surface area of hammer exposed to blood, the angle of inclination at which the hammer falls as also the edge, face or other part of the hammer that first strikes the surface influence the formation of the transfer stain.
Again in this respect, it would not be out of place to mention that even if a hammer is dropped face down in a $30 \mathrm{cc}$. blood pool, it is not necessary that the entire front face of the hammer will get soaked in blood. The flow of blood pool is often majorly restricted due to viscosity and other external obstructions. Hence when 
a hammer falls in a blood pool under gravity, the portion of the hammer in blood pool displaces volume of blood that is equal to the volume of the portion of hammer that is fully or partly immersed in blood (CDAC Mumbai, 2014). Given the hammer dimensions, the volume of blood in the pool determines to what extent the hammer will be soaked/immersed in the pool. Now as displayed in Figure 4, all parts of the hammer are not at the same level, hence do not touch the ground. So the $30 \mathrm{cc}$. blood pool that does not have much or rather varying depth along its length might not come in contact with the part of the hammer that is a bit above the surface. This part is marked out by a red right angled triangle in Figure 4. By way of experimentation the authors arrived at the conclusion that the angle of inclination of the hammer at fall as also the orientation of the hammer at which it starts falling decides which part of the hammer would touch the target surface first. Again, certain parts of the hammer may not even fall in the blood pool or might have very few blood molecules attached to the surface depending on the volume of blood in the blood pool in comparison with the volume of the hammer. Hence even if a hammer drops in a blood pool after 10 head hits and is picked up from the pool and allowed to fall bloody face down from a height of 40,60 and $80 \mathrm{cms}$ respectively, then a complete bloody transfer stain of the hammer face might not be formed on a plain/smooth, non-absorbent, non-porous surface.

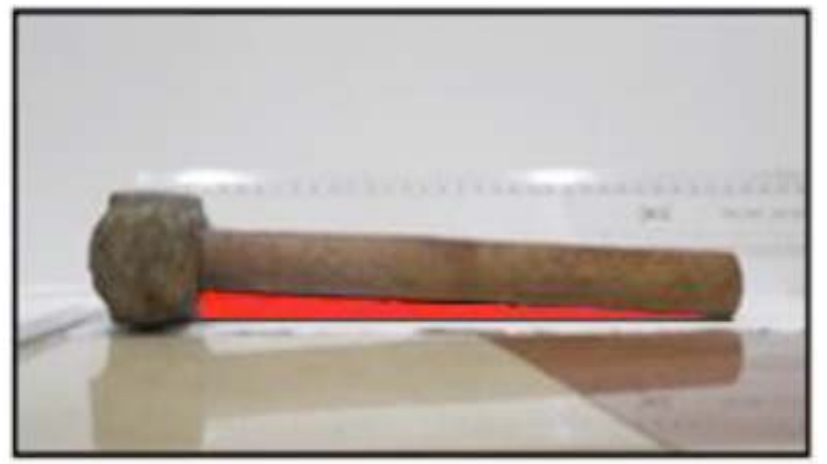

Figure 4: The side view of a sledge hammer (HS4). The red colored triangle represents the area of the hammer that doesn't come into direct contact with the ground when the hammer is placed on the ground.

In substantiating Hypothesis 2, one could very well refer to and hence compare Figure E1.1 and Figure EF1.1 (refer Figure 5). Figure E1.1 represents the transfer stain formed when an edge of the ball peen hammer was placed on a plain, non-absorbent paper surface and held in that position for a minimum of 5 secs.

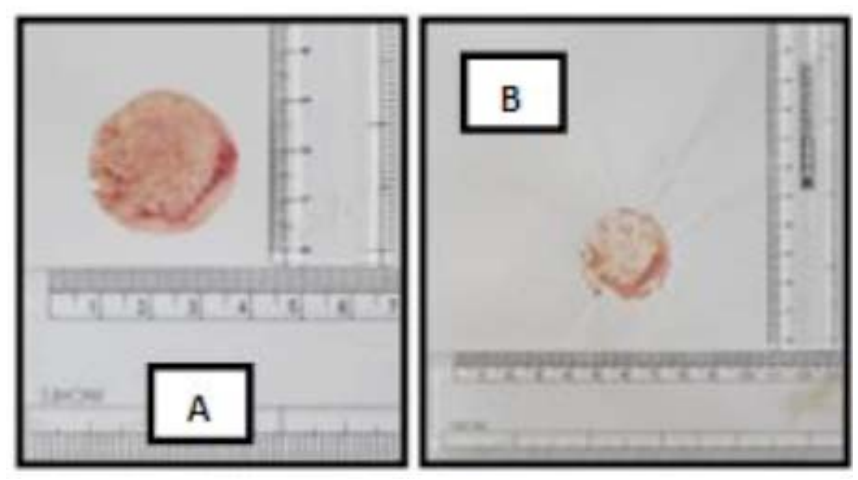

Figure 5: A comparative image of the transfer stains cast by the same edge of the ball peen hammer. A) Represents stain in Figure E1.1, B) Represents stain in Figure EF1.1.

The paper creases in the Figure EF1.1 clearly testify that the Initial impact velocity when the hammer hit the paper surface placed on a thermocol sheet was far greater than that in the previous case (i.e. formation of $E 1.1)$, thereby causing a significant displacement $x$ (refer Figure 6) (Hammer Physics, 2013).

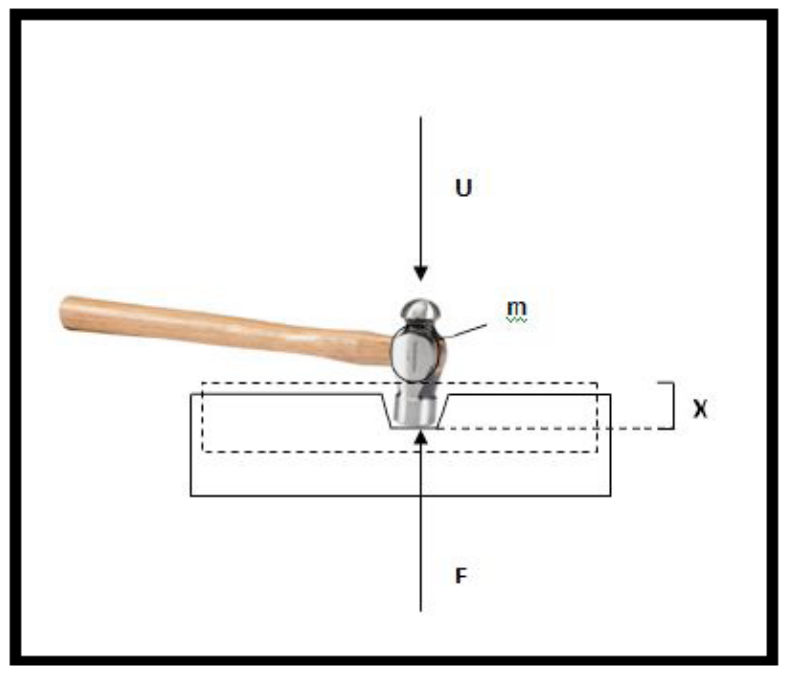

Figure 6: Image representing the event of a hammer hit on a surface. $U$ represents the velocity of initial impact, $m$ represents the mass of the hammer head, $F$ represents the normal force cast by the surface on the hammer and $x$ represents the displacement made before the hammer finally decelerates to zero velocity. The acceleration $a=U^{2} / 2 x$, Impact Force $=\mathrm{m} \times$ a $($ Hammer Physics, 2013).

Paper is much softer than iron (the material the hammer head is made up of) hence when hit with a certain amount of Initial impact velocity that is not large it sags with crease formation on the surrounding. For an even larger initial Impact velocity it tears off (refer Figure 7).

Now based on relative hardness, when a softer substance/surface is struck by a relatively harder substance/surface, as per theory the softer 


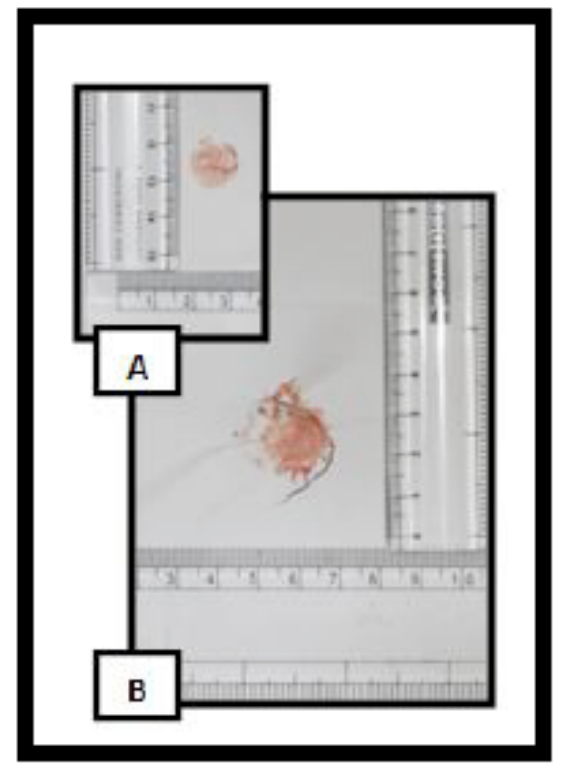

Figure 7: A) Stain formed when round edge of cross peen and straight hammer was used for 10 head hits and then placed on plain, non-absorbent paper. B) Stain formed when the same edge after 10 head hits was used to hit plain, nonabsorbent paper surface with a comparatively larger initial impact velocity thereby leading to rupture of paper surface.

substance/surface gets scratched (Wredenberg, F, \& Larsson, PL, 2009). The hardness of a material (say iron) is measured against the Mohs scale by finding out the hardest substance/material that the substance/material under consideration can scratch and the softest material that can scratch the given substance/material (Wredenberg, F, \& Larsson, PL, 2009). When it comes to substances that are harder than paper and again softer than the material with which the hammer head is built (cast iron in this case) such as certain flooring marble slab, scratches are formed when hit by the hammer with a certain initial impact velocity. For larger initial impact velocities cracks are formed (refer Figure 8) (Wredenberg, F, \& Larsson, PL, 2009).

To be more precise, when the target substance is softer and the initial impact force exceeds the normal force, cracks and dents are formed. Hence bloodstain transfer pattern is particularly affected by the variation in the quantity of blood attached to the edge, initial impact velocity, and relative hardness/softness of the target surface material.

When the same amount of blood was allowed to drop from a height of $10 \mathrm{cms}$ and a height of $100 \mathrm{cms}$, a difference in the size/diameter of the blood drop was recorded. In the same context, when blood drips from a greater height one would expect it to spatter more (CLT, 2014). The Impact force resulting when a body of

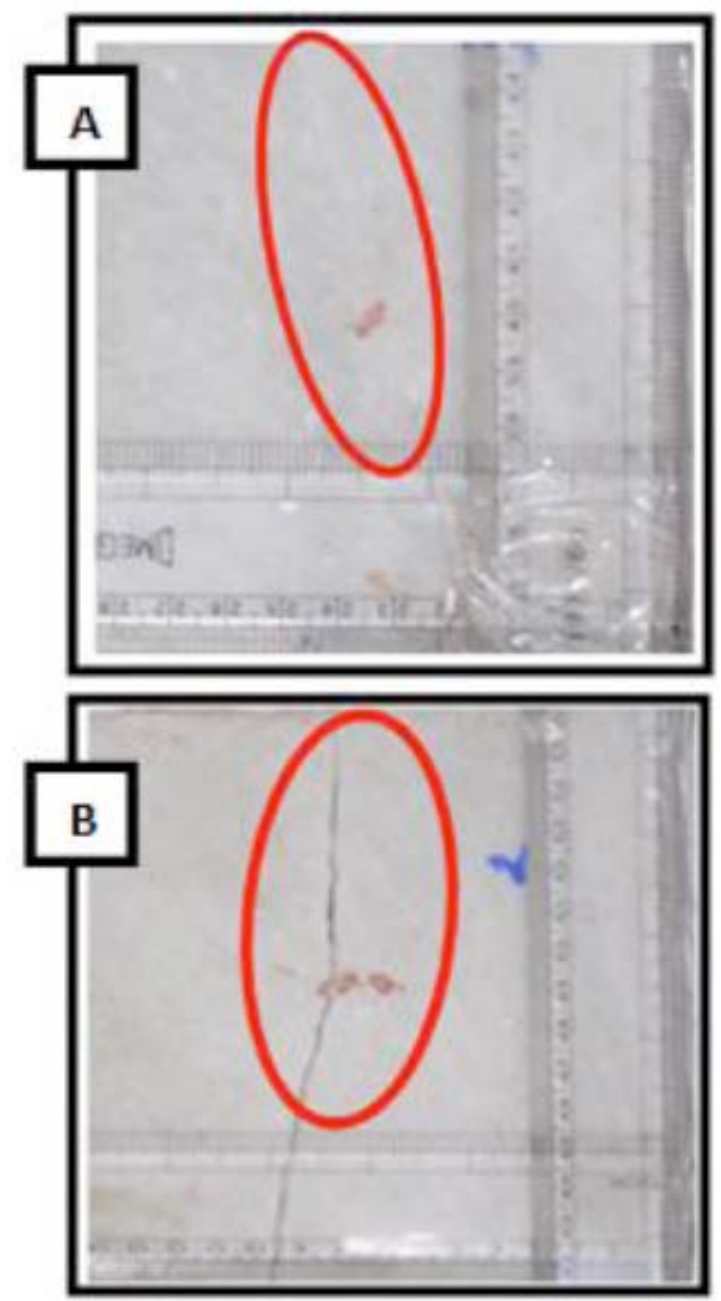

Figure 8: A) Marble slab used for flooring when hit with a particular velocity by a bloody ball peen hammer edge after 10 consecutive head hits results in scratch formation B) Marble slab hit with higher initial impact velocity by the same edge of the ball peen hammer after 10 consecutive head hits results in formation of a crack.

mass M (refer HW4 and HW7) falls solely under the action of gravity and air resistance acting in the opposite direction through a height $\mathrm{H}$ and then interacts with the target surface for an interval of time $\Delta \mathrm{T}$, then the force is directly proportional to the mass as also to the square root of fall height (Newton's Law of Gravity). Thus height (refer HW1, HW2 and HW3) does have an impact on the force at which the object hits the surface. The greater the force of impact, the more one could expect the blood attached on the surface of the object to spatter and hence form satellites as because the force is more likely to exceed the surface tension of blood. Again, an elongated object or a top heavy elongated object (like a hammer) when dropped to the ground will have a falling or rotating phase (refer Figure HW4) while it remains in contact with the ground or target surface (Cross, R, 2006). This centripetal force 
on the object acts towards reducing the normal reaction force exerted by the ground or target surface on the object (in this case hammer). The initial angle of inclination at which the hammer is dropped, the coefficient of friction, the length and mass distribution of a hammer influence the magnitude and direction of displacement of the hammer as also the stain pattern one could expect to see in case of a blood bearing hammer (Cross, R, 2006). Thus the height of fall, the quantity of blood attached to the surface of hammer, the inclination at which the hammer is dropped, friction coefficient of the material of hammer, length and mass distribution of the hammer and the edge at which the hammer strikes the target surface influence the transfer stain pattern formed, thereby evidentially substantiating Hypothesis 3.

The authors are aware of the fact that the muscle layer and hence the embedded arterial network is not uniform across the entire human skull hence the amount of blood that could get attached to the hammer end used to hit an individual also depends on the area of head hit together with the velocity of hit (Platysma muscle, 2014).

\section{CONCLUSION}

The quantity of blood that adheres to a hammer, the surface area of the hammer to which the blood molecules adhere, the angle of inclination at which the bloody hammer drops, the length and mass distribution of hammer, coefficient of friction, the edge at which it hits the surface have significant effect on the blood transfer stain of hammer formed on a Plain/smooth, non-absorbent surface. Again, the velocity or rather the impact force generated by hammer hit or by hammer free fall, material of the target surface, area of the head hit with the said hammer also have significant effect on the transfer stain formed on a plain/smooth, non absorbent surface. However, in the absence of a murder weapon at the crime scene, apparent hammer transfer stains need to be studied in the light of other circumstantial evidence such as wound analysis, absence/presence of objects at the crime scene, other transfer stains, cast off patterns formed on the wall/ceiling etc at a crime scene.

This work could very well be extended to study/understand transfer stains produced by other elongated and elongated top-heavy murder weapons such as candle stand, golf stick, wooden mallet, axe etc. Given the large variability in the number of tools that can be used as murder weapons (elongated and top heavy elongated), variability in the material of these tools, varying texture and material of the target surface, varying impact force generated, it is difficult to develop an automated computerized tool for analyzing transfer stain patterns. To develop a tool that is efficient at analyzing and probabilistically predicting possible tools that could have created a particular sort of transfer stain, development of a dataset consisting of a large variety of weapon transfer stains formed by different angle of inclination of tool drop, dimension of tool edge, fall height, velocity of hit etc. stands integral. However for development of a tool, development of a database that has sufficient variation and comparable representation of each possible class type stands out to be the biggest challenge. Once a dataset has been drawn up, semi-supervised learning techniques could be used to develop an appropriate tool.

From practical experience, the authors are of the opinion that in the absence of a murder weapon at the crime scene, study of other circumstantial evidence such as wound analysis, absence/presence of objects at a crime scene, cast off patterns, drip trails, impact spatter etc. in correlation with weapon transfer stain patterns (if any) shall help analysts in identifying the most probable tool that has been used for the murder or for injuring the victim who might not be in a position to narrate the sequence of events. Based on analysis of weapon transfer stain patterns, the factors highlighted in this study shall help pattern analysts in part/full sequencing of probable events that might have occurred at the crime scene. Hence, this study shall aid effective part reconstruction of criminal events.

\section{ACKNOWLEDGEMENT}

At the very onset, the authors would like to thank Dr. Silke Brodbeck for providing the authors with bloodstain pattern analysis domain knowledge. The authors would like to thank all members of the Kolkata Municipal Pig Slaughter House located at Tangra, Kolkata, India for allowing them to collect blood from the slaughter house. Not only procurement, the members at the Kolkata Municipal Pig slaughter house also assisted the authors in properly disposing of unused blood. This work was undertaken within the premises of NSHM Knowledge Campus, Kolkata. Hence, the authors would particularly want to extend their gratitude to all members of NSHM Knowledge Campus Kolkata, for providing them with proper laboratory facility. The authors would also like to acknowledge the help extended by Mr. Neelava Biswas in conducting the experiments. The authors truly 
believe that this work would not have been possible without the help and support of all these people.

\section{REFERENCES}

Amin, T. M., \& Sirs, J. A. (1985). The blood rheology of man and various animal species. Quarterly Journal of Experimental Physiology (70, 37-49. Retrieved from http://ep.physoc.org/ content/70/1/37.long

Barksdale, L., Sims, E., \& Vo, C. (2004). Knife Impression Bloodstain Patterns. Crime Scene Investigation Special Issue Anil Aggrawal's Internet Journal of Forensic Medicine \& Toxicology. Retrieved from http://www.geradts.com/ anil/ij/ indexpapers.html

Bevel, T., \& Gardner, R. M. (2002). Bloodstain pattern analysis: With an introduction to crime scene reconstruction (3rd ed.).

Blanco, J. I. (n.d.). Adam Moss | Murderpedia, the encyclopedia of murderers. Retrieved October 17, 2014, from http://murderpedia.org/male.M/m/moss-adam.htm

Blanco, J. I. (n.d.). Alexander Pichushkin | Murderpedia, the encyclopedia of murderers. Retrieved October 17, 2014, from http://murderpedia.org/male.P/p/pichushkin-alexander. $\mathrm{htm}$

Blanco, J. I. (n.d.). Blackwell Brian | Murderpedia, the encyclopedia of murderers. Retrieved October 18, 2014, from http://murderpedia.org/male.B/b/blackwell-brian.htm

Blanco, J. I. (n.d.). Christine Schurrer | Murderpedia, the encyclopedia of murderers. Retrieved October 17, 2014, from http://murderpedia.org/female.S/s/schurrer-christine.htm

Blanco, J. I. (n.d.). Kampatimar Shankariya | Murderpedia, the encyclopedia of murderers. Retrieved October 18, 2014, from http://murderpedia.org/male.S/s/shankariya.htm

Blanco, J. I. (n.d.). Ma Jiajue | Murderpedia, the encyclopedia of murderers. Retrieved October 17, 2014, from http://www.murderpedia.org/male.J/j/jiajue-ma.htm

Blanco, J. I. (n.d.). Maoupa Cedric Maake | Murderpedia, the encyclopedia of murderers. Retrieved October 17, 2014, from http://murderpedia.org/male.M/m/maake-maoupa.htm

Blanco, J. I. (n.d.). Murderpedia, the encyclopedia of murderers. Retrieved October 18, 2014, from http://murderpedia.org/

Brodbeck, S. (2012). Introduction to Bloodstain Pattern Analysis. SIAK Journal- Journal of Police Science and Practice, 2, 5157. doi:10.7396/IE_2012_E

CDAC Mumbai, \& Amrita University (n.d.). Verification of Archimedes' Principle (Theory) : Class 9 : Physics : Amrita Online Lab. Retrieved October 20, 2014, from http://amrita.olabs.co.in/? $\mathrm{sub}=1 \& \mathrm{brch}=1 \& \operatorname{sim}=72 \& \mathrm{cnt}=1$

Centre for Learning Technology, University of Western Australia. (n.d.). Centre for Learning Technology. Retrieved October 17, 2014, from http://www.clt.uwa.edu.au/ data/assets/ pdf_file/0017/2301650/fsb05.pdf

Christman, D.V., A Study to Compare and Contrast Animal Blood to Human Blood Product. International Association of Bloodstain Pattern Analysts News, 1996. 12(2): p. 10-25
Cross, R. (2006). The fall and bounce of pencils and other elongated objects. American Journal of Physics, 74(1). http://dx.doi.org/10.1119/1.2121752

Hammer Physics. (2013). Retrieved from Truth4Inge.com website: http://www.truth4inge.com/Hammer_Physics_web.pdf

Illes, M., \& Boue, M. (2011). Investigation of a Model for Stain Selection in Bloodstain Pattern Analysis. Canadian Society of Forensic Science, 44(1), 1-12. http://dx.doi.org/10.1080/00085030.2011.10768137

James, S. H. (1998). Scientific and legal applications of bloodstain pattern interpretation. Boca Raton, FL: CRC Press.

James, S. H., Kish, P. E., \& Sutton, T. P. (2005). Principles of bloodstain pattern analysis: Theory and practice. Boca Raton, FL: CRC http://dx.doi.org/10.1201/9781420039467

Newton's Law of Gravity. (n.d.). Retrieved October 18, 2014, from http://www.splung.com/content/sid/2/page/gravitation

Nordby, J. J. (2006). Final Analysis Forensics. Retrieved from http://www.finalanalysisforensics.com/media/pdfs/BasicBlood stainPatternAnalysisTEXT.pdf

Platysma muscle. (n.d.). In Wikipedia, the free encyclopedia. Retrieved November 14, 2014, from http://en.wikipedia.org/ wiki/Platysma_muscle

Ristenbatt III, R. R. (2009). Review of: Bloodstain Pattern Analysis with an Introduction to Crime Scene Reconstruction, 3rd edition. Journal of Forensic Sciences, 54(1). http://dx.doi.org/10.1111/j.1556-4029.2008.00932.x

Scientific Working Group On Bloodstain Pattern Analysis. (2009, April). FBI - Standards and Guidelines - Scientific Working Group on Bloodstain Pattern Analysis: Recommended Terminology - April 2009. Retrieved from http://www.fbi.gov/ about-us/lab/forensic-science-communications/fsc/april2009/ standards/2009_04_standards01.htm

Shen, A. R., Brostow, G. J., \& Cipolla, R. (0). TOWARD AUTOMATIC BLOOD SPATTER ANALYSIS IN CRIME SCENES. Retrieved from http://mi.eng.cam.ac.uk/research/ projects/BloodSpatter/BloodSpatter_ShenBrostow.pdf

Toplikar, D. (2010, December 13). Blood stain with hammer imprint shown in ex-FBI agent's murder trial - Las Vegas Sun News. Retrieved from http://www.lasvegassun.com/news/2010/dec/ 13/blood-stain-showed-imprint-hammer-says-analyst-ex-/

Washington CBS Local. (2013, January 3). FBI: Hammers, Clubs Kill More People Than Rifles, Shotguns « CBS DC. Retrieved October 20, 2014, from http://washington.cbslocal.com/ 2013/01/03/fbi-hammers-clubs-kill-more-people-than-riflesshotguns/

Welding, S. (2012, 12). Locard's Exchange Principle - Forensic HandbookForensic Handbook. Retrieved October 22, 2014, from http://www.forensichandbook.com/locards-exchangeprinciple/

Wredenberg, F., \& Larsson, P. L. (2009). Delamination of thin coatings at scratching: experiments and numerics. Journal of Mechanics of Materials and Structures, 4(6). http://dx.doi.org/10.2140/jomms.2009.4.1041

\section{DOI: http://dx.doi.org/10.6000/1929-4409.2014.03.34}

(C) 2014 Bandopadhyay and Basu; Licensee Lifescience Global.

This is an open access article licensed under the terms of the Creative Commons Attribution Non-Commercial License (http://creativecommons.org/licenses/by-nc/3.0/) which permits unrestricted, non-commercial use, distribution and reproduction in any medium, provided the work is properly cited. 